\title{
Metal-Organic Framework Thin Film-Based Dye Sensitized Solar Cells with Enhanced Photocurrent
}

\author{
Shargeel Ahmad ${ }^{1}$, Jinxuan Liu ${ }^{1, *} \mathbb{B}$, Wei Ji ${ }^{1}$ and Licheng Sun ${ }^{1,2}$ \\ 1 State Key Laboratory of Fine Chemicals, Institute of Artificial Photosynthesis, Dalian University of \\ Technology, Dalian 116024, China; shargeel@mail.dlut.edu.cn (S.A.); jiwei@dlut.edu.cn (W.J.); \\ sunlc@dlut.edu.cn (L.S.) \\ 2 Department of Chemistry, School of Chemical Science and Engineering, KTH Royal Institute of Technology, \\ 10044 Stockholm, Sweden \\ * Correspondence: jinxuan.liu@dlut.edu.cn
}

Received: 5 September 2018; Accepted: 28 September 2018; Published: 1 October 2018

check for updates

\begin{abstract}
Metal-organic framework thin film-based dye sensitized solar cell is fabricated with highly oriented, crystalline, and porous Zn-perylene metal-organic framework (MOF) thin film (SURMOF) which is integrated with Bodipy embedded in poly(methyl methacrylate). It has been demonstrated that the photocurrent can be enhanced by a factor of 5 relative to Zn-perylene MOF thin film due to triplet-triplet annihilation up-conversion between the Bodipy/PMMA sensitizer and the Zn-perylene $\mathrm{MOF}$ thin film acceptor using $\mathrm{Co}(\mathrm{bpy})_{3}{ }^{2+/ 3+}$ as redox mediator.
\end{abstract}

Keywords: surface supported metal organic framework; triplet-triplet annihilation upconversion; triplet-triplet energy transfer; dye sensitized solar cell

\section{Introduction}

The fabrication of triplet-triplet annihilation up-conversion (TTA-UC) solar cell device is one of the ongoing interests to overcome the energy loss with suitable energy conversion materials [1-3]. The TTA-UC based solar cell devices can overcome the Shockley-Queisser limitations, enhance the efficiency and most importantly decrease the cost [4]. The self-assembled bilayers of sensitizer (S) and acceptor (A) pair on top of metal oxide surface have been reported as one of the promising strategy to enhance the photocurrent via triplet-triplet annihilation (TTA-UC), which can effectively be utilized for dye sensitized solar cells (DSSC) [5]. Surface-anchored metal-organic frameworks (SURMOFs) with controlled growth orientation, regular monolithic porous crystalline frameworks show potential applications in gas separation [6], electronics [7-9], $\mathrm{CO}_{2}$ reduction [10-13], water splitting [14,15], photovoltaics [16-18], and most recently in TTA-UC system [19,20]. As one of the potential energy materials, the use of SURMOFs for solar energy conversion [16], in particular DSSC, is challenging due to the poor solar capture ability and photo-induced charge carrier mobility, which lead to the sever charge recombination and weak photocurrent. Therefore, it is highly desirable to develop the strategy to enhance the photocurrent in a SURMOF-based DSSC.

In TTA-UC process (Figure 1$)$ the photons with low energy $\left(\mathrm{hv}_{1}\right)$ are absorbed to generate photons of higher energy $\left(\mathrm{hv}_{2}\right)$ via Dexter type energy transfer mechanism [21] by using low intensity light, followed by energy transfer: (a) first, generation of singlet excited state in sensitizer $\left(\mathrm{S}_{1}\right)$; (b) intersystem crossing (ISC) from singlet into triplet $\left(\mathrm{T}_{1}\right)$; $(\mathrm{c})$ triplet-energy-transfer (TEnT) from the sensitizer to the acceptor; (e) creating the singlet excited state of acceptor through TTA-UC mechanism; (f) finally, the acceptor/emitter emits from its singlet state (Figure 1) [20]. 


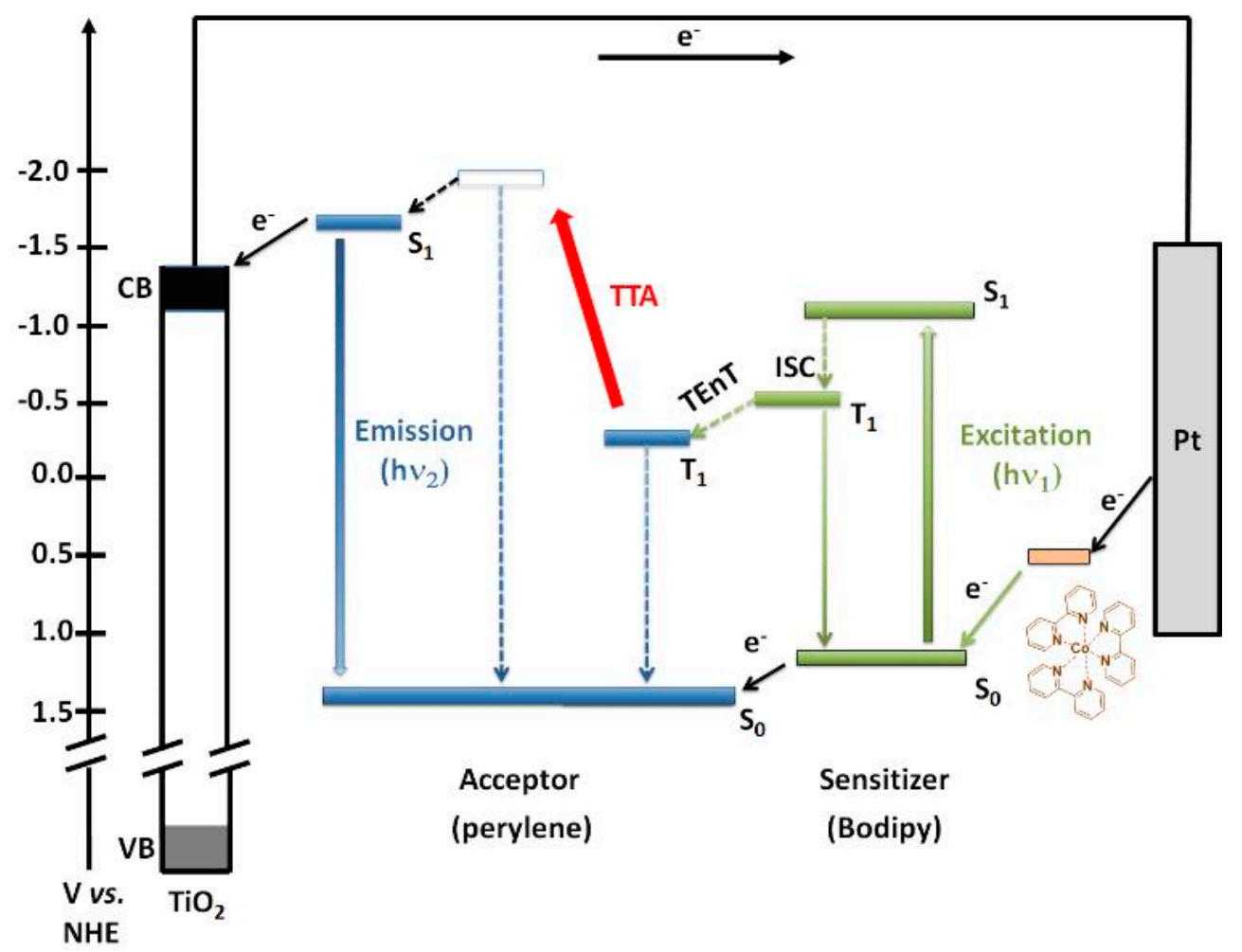

Figure 1. Schematic illustration of energy level diagram of triplet-triplet annihilation up-conversion in DSSC. TEnT: triplet energy transfer.

An intermediate band solar cell was fabricated in which the conduction band and valance band allow enhanced photovoltaic efficiencies via TTA-UC mechanism [3]. The solar cells based on TTA-UC mechanism have dramatically enhanced photocurrent up to $0.275 \mathrm{~mA} \cdot \mathrm{cm}^{-2}$ under 19 equivalent suns [22,23]. Hill et al. has reported a promising material for dye sensitized solar cell (DSSC) with $\mathrm{TiO}_{2}$-DPPA-Zn-PtTCPP films (bilayer) (DPPA = 4,4-(anthracene-9,10-diyl)bis(4,1-phenylene) diphosphonic acid, $\mathrm{PtTCPP}=\operatorname{Pt}(\mathrm{II})$ tetrakis(4-carboxyphenyl)porphyrin) to enhance the photocurrent via TTA-UC [1,24].

We have reported previously an epitaxial MOF thin film-based photoelectrochemical device by using highly oriented surface-anchored MOF thin film (SURMOF), Zn-perylene SURMOF as acceptor, and PtOEP (PtOEP $=\mathrm{Pt}(\mathrm{II})$ octaethylporphine) as sensitizer in acetonitrile solution [19]. Under green light irradiation, the sensitizer absorbs the photons and transfers the triplet energy to perylene molecules within SURMOFs, followed by the TTA-UC, leading to the enhancement of photocurrent. However, the sensitizers are dissolved in electrolyte solution and randomly contacted with perylene molecules of $\mathrm{Zn}$-perylene SURMOF thin film surface. Therefore, the quenching of oxygen and high local mobility of the sensitizers during TTA-UC process hinders the photocurrent generation efficiency. On the other hand, the metalloporphyrins used as sensitizers for realization of TTA-UC increase the cost of SURMOF-based photovoltaic devices.

Herein, for the first time, we report an approach by assembling metal-free sensitizer, Bodipy derivative with poly(methyl methacrylate) (PMMA) [25-27] on-COOH exposed Zn-perylene SURMOF surface. Recently, the promising idea to use the polymers for the TTA-UC process has been reported [28]. The synthesis and characterizations of the Bodipy derivative (Figures S1 and S2) can be found in Supporting Information.

Further, we assembled this material into a dye-sensitized solar cell (DSSC) and demonstrated the enhancement of photocurrent via TTA-UC in the presence of Co (bpy) $)_{3}{ }^{2+/ 3+}$ redox mediator as illustrated in Figure 2. 


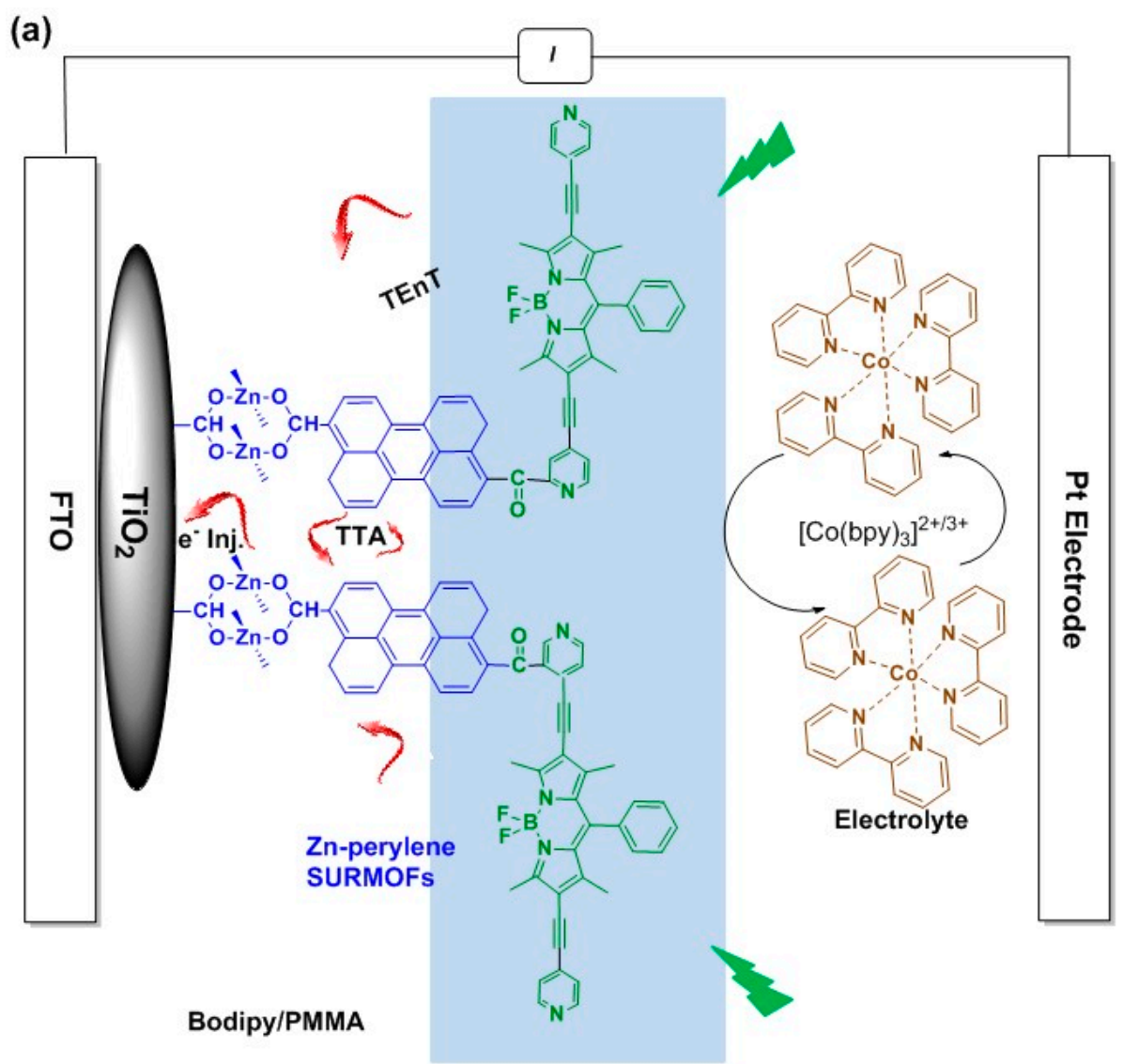

(b)

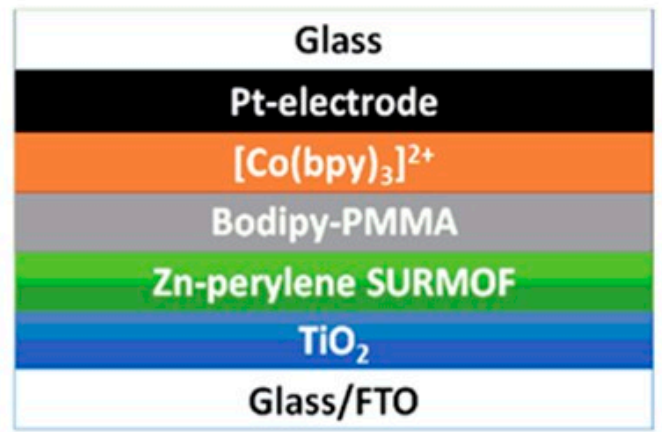

Figure 2. (a) Schematic representation of $\mathrm{Zn}$-perylene SURMOF on $\mathrm{TiO}_{2}$ and Bodipy/PMMA layer; (b) the architecture of Zn-perylene SURMOF-based dye sensitized solar cell.

The highly crystalline and well oriented Zn-perylene SURMOF with a thickness of $\sim 600 \mathrm{~nm}$ was prepared on top of $\mathrm{TiO}_{2}$ according to our previously reported protocol [19]. In the next step, the - $\mathrm{COOH}$ exposed Zn-perylene SURMOF was modified with Bodipy sensitizers [29] and PMMA via photochemical reaction which formed a glassy film of Bodipy/PMMA on top of $\mathrm{TiO}_{2}-\mathrm{Zn}$-perylene SURMOF (Figure S3). The detailed fabrication procedure can be found in Supporting Information.

\section{Results and Discussions}

The ultraviolet-visible (UV-vis) spectrum of Zn-perylene SURMOF is shown in Figure 3 (in black). Compared with the UV-vis spectrum of free perylene dicarboxylic acids (438 nm and $460 \mathrm{~nm}$ in acetonitrile solution, Figure S4), Zn-perylene SURMOF shows absorption band at $420 \mathrm{~nm}$ and $470 \mathrm{~nm}$, which are associated to the $S_{1}\left(B_{1 u}\right) \leftarrow S_{0}\left(A_{g}\right)$ transition of perylene units [30]. After integration of as 
prepared SURMOF with Bodipy/PMMA, a new absorption band at $560 \mathrm{~nm}$ was observed, which can be attributed to the $\pi-\pi^{*}$ transition of Bodipy compounds [31].

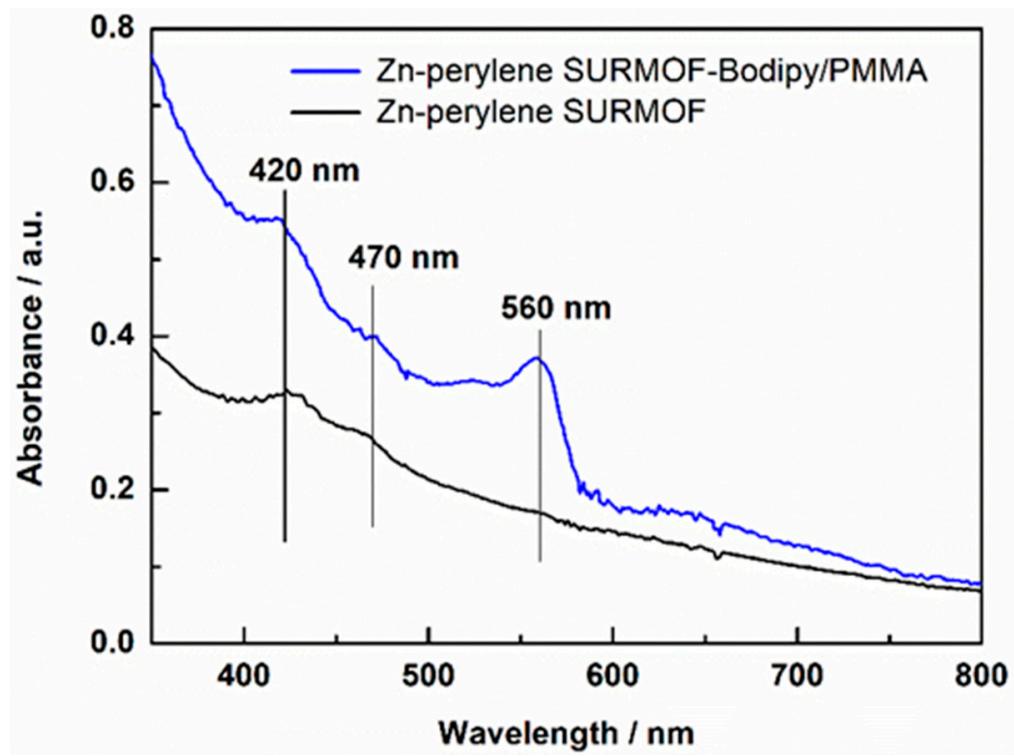

Figure 3. UV-vis spectra of Zn-perylene SURMOF-Bodipy /PMMA (in blue) and Zn-perylene SURMOF (in black).

The fabricated hybrid material was further characterized by infrared (IR) spectroscopy as shown in Figure S5. The Zn-perylene SURMOF-Bodipy/PMMA material showed two strong bands appeared at $1746 \mathrm{~cm}^{-1}$ and $1725 \mathrm{~cm}^{-1}$ which can be attributed to the carbonyl group of PMMA [32]. Due to the small amount of Bodipy in PMMA, the vibrational bands of Bodipy are overlapped with the bands of PMMA and Zn-perylene SURMOF (Table S1).

A SURMOF-based DSSC device was fabricated according to previously reported protocol [16] as shown in Figure 2b. We rationalized to utilize the new materials of Zn-perylene SURMOF-Bodipy / $\mathrm{PMMA} / \mathrm{TiO}_{2}$ as photoanode, platinum as counter electrode and $\mathrm{Co}(\mathrm{bpy})_{3}{ }^{2+/ 3+}$ as redox mediator in acetonitrile solution. The detailed fabrication procedure can be found in Supporting Information.

The chronoamperometric (i-t) experiments were performed by using $\mathrm{TiO}_{2}$ - $\mathrm{Zn}$-perylene SURMOF-Bodipy/PMMA, $\mathrm{TiO}_{2}-\mathrm{Zn}$-perylene SURMOF and $\mathrm{TiO}_{2}$ as photo anode and platinum as counter electrode in $\mathrm{Co}(\mathrm{bpy})_{3}{ }^{2+/ 3+}$ acetonitrile solution with an external potential $0 \mathrm{~V}$ vs $\mathrm{Ag} / \mathrm{AgNO}_{3}$. A $532 \mathrm{~nm}$ green light (power: $\sim 80 \mathrm{~mW} \cdot \mathrm{cm}^{-2}$ ) coupled with an automatic shutter was used to control the light irradiation-i.e., light on and light off.

As shown in Figures 4a and S6, under the $532 \mathrm{~nm}$ light irradiation, the transient photocurrents of $\sim 1.25 \mu \mathrm{A} \cdot \mathrm{cm}^{-2}, \sim 0.25 \mu \mathrm{A} \cdot \mathrm{cm}^{-2}$, and $\sim 0.1 \mu \mathrm{A} \cdot \mathrm{cm}^{-2}$ are obtained for $\mathrm{TiO}_{2}-\mathrm{Zn}$-perylene SURMOF-Bodipy/PMMA, $\mathrm{TiO}_{2}-\mathrm{Zn}$-perylene SURMOF and $\mathrm{TiO}_{2}$, respectively. The photocurrent was enhanced nearly 5 -fold compared to that of $\mathrm{TiO}_{2}-\mathrm{Zn}$-perylene SURMOF and $\mathrm{TiO}_{2}$.

It has been reported that the distance between photosensitizer and acceptor should be between agreeable levels to enhance the energy via TTA-UC [2]. The addition of solidified PMMA with Bodipy on top of - $\mathrm{COOH}$ exposed Zn-perylene MOF thin film has considerably contributed for the energy conversion performance of the materials [33]. As shown in Figure $\mathrm{S} 13$ that $\mathrm{TiO}_{2}-\mathrm{Zn}$-perylene SURMOF + Bodipy/PMMA has greater solar energy conversion performance than $\mathrm{TiO}_{2}-\mathrm{Zn}$-perylne SURMOF, $\mathrm{TiO}_{2}$-Bodipy/PMMA, and $\mathrm{TiO}_{2}$-electrolyte. Therefore, the strategy to utilize novel $\mathrm{Zn}$-perylene SURMOF-Bodipy/PMMA materials shows potential applications for DSSC. 
(a)

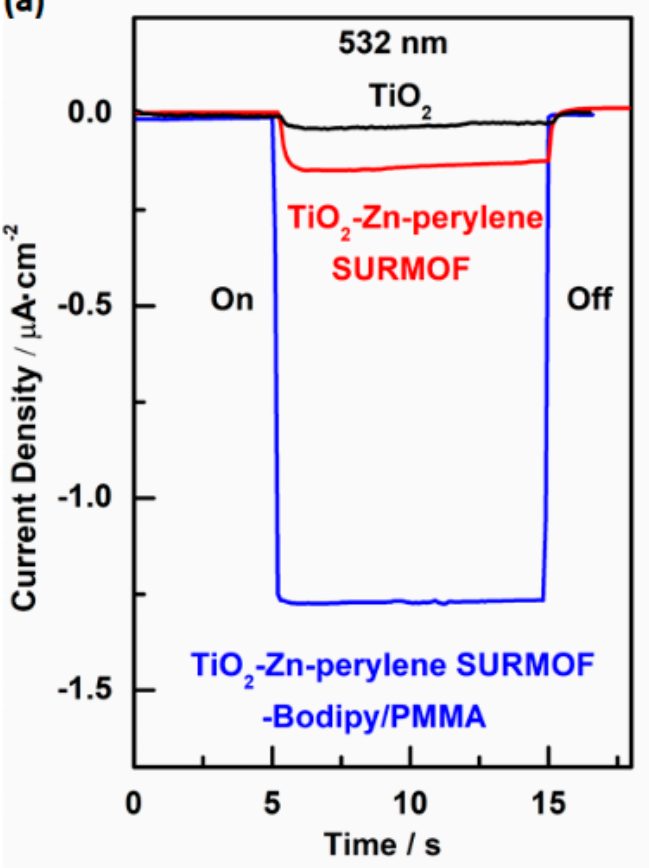

(b)

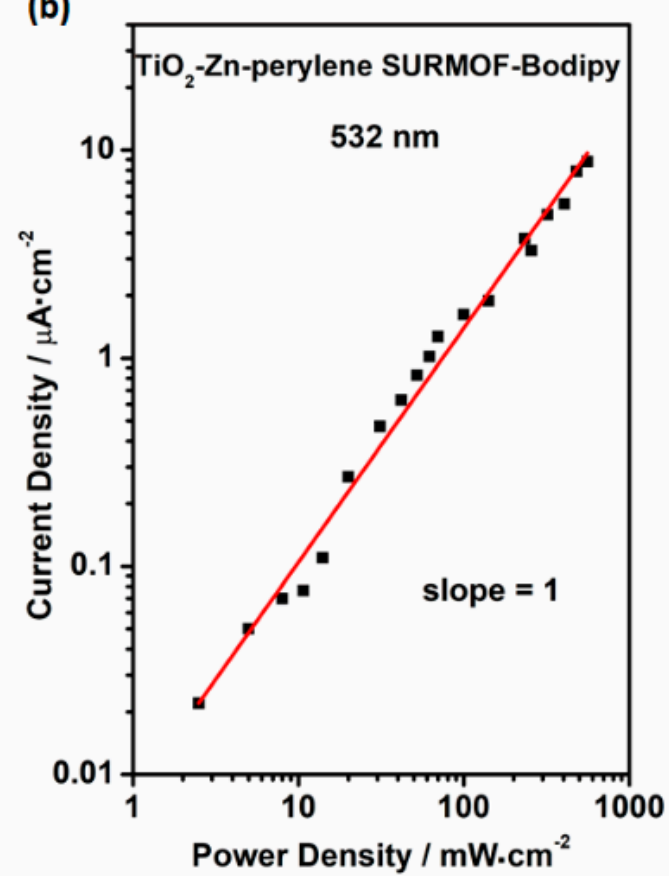

Figure 4. (a) The i-t curves for DSSCs composed of $\mathrm{TiO}_{2}-\mathrm{Zn}$-perylene SURMOF-Bodipy/PMMA, $\mathrm{TiO}_{2}-\mathrm{Zn}$-perylene SURMOF, and $\mathrm{TiO}_{2}$ as photoanodes and $\mathrm{Co}(\mathrm{bpy})_{3}{ }^{2+/ 3+}$ as redox mediator under the $532 \mathrm{~nm}$ light irradiation (power: $\sim 80 \mathrm{~mW} \cdot \mathrm{cm}^{-2}$ ). (b) The current density of $\mathrm{TiO}_{2}-\mathrm{Zn}$-perylene SURMOF-Bodipy/PMMA under $532 \mathrm{~nm}$ green light irradiation with different power intensity.

In order to have a deep understanding about the mechanism of photocurrent enhancement, we have carried out fluorescence experiment by using perylene dicarboxylic acid as acceptor and Bodipy as sensitizer in acetonitrile solution as shown in Figure S7. Upon excitation wavelength of $532 \mathrm{~nm}$ for the perylene dicarboxylic acid + Bodipy system the emission signal at $496 \mathrm{~nm}$ and $582 \mathrm{~nm}$ was observed (Figure S7 inlet) which can be attributed to emission signal from perylene dicarboxylic acid and Bodipy emission. As a reference the emission spectra of biphenyl dicarboxylic acid + Bodipy in deaerated acetonitrile was displayed in Figure S8, which gives no emission signal indicating that the TTA-UC cannot occur between biphenyl unit and Bodipy. Based on the above-mentioned results, we have proposed the TTA-UC mechanism to explain the photocurrent enhancement for Zn-perylene SURMOF + Bodipy system. Upon $532 \mathrm{~nm}$ excitation, the triplet energy generated from Bodipy sensitizer with higher energy and long-lived life time allows them to efficiently transfer triplet energy (via triplet energy transfer (TEnT)) to the Zn-perylene SURMOF acceptor. The perylene molecules annihilate the triplet energy via TTA-UC to generate the excited singlets which diffuse through the $\mathrm{Zn}$-perylene SURMOF to the interface between $\mathrm{Zn}$-perylene $\mathrm{SURMOF}$ and $\mathrm{TiO}_{2}$, where the charge separation occurs and the generated electrons are injected into the $\mathrm{TiO}_{2}$ for photocurrent enhancement (Figure 2a).

In addition, the power intensity dependent current density experiment which is one of the standard measurements for support of TTA-UC mechanism was carried out as displayed in Figure $4 \mathrm{~b}$. Upon $532 \mathrm{~nm}$ green light excitation, a linear response was obtained from all power range which is different from quartic to linear behavior observed in $\mathrm{TiO}_{2}-\mathrm{Zn}$-perylene SURMOF-PtOEP (PtOEP $=$ $\mathrm{Pt}(\mathrm{II})$ octaethylporphine) [19] due to the efficient TEnT process [30], which favors the up-conversion process with a linear relationship than a quadratic relationship [27,34].

The Bodipy sensitizers encapsulated in solid-state-like PMMA film material can overcome the non-radiative decay process and assist the efficient TEnT from Bodipy to Zn-perylene SURMOF (acceptor) as schematically shown in Figure 1. In such a system, the generated triplets from photosensitizers have enough time to transfer triplet energy more efficiently to the acceptor and 
go through TTA-UC to produce photocurrent with $\mathrm{TiO}_{2}$-Zn-perylene SURMOF-Bodipy/PMMA device (Figure 2a).

It is inferred that the quenching effect in $\mathrm{TiO}_{2}$ - $\mathrm{Zn}$-perylene SURMOFs-Bodipy/PMMA materials based device can be suppressed, where the generated triplet energy from Bodipy sensitizer can be efficiently transferred to the acceptors and further generate enhanced photocurrent via TTA-UC [24].

Nanosecond transient absorption spectroscopy (TAS) measurement has been performed to characterize the triplet lifetime of Bodipy in acetonitrile with and without the presence of $\mathrm{O}_{2}$ as shown in Figures S9 and S10. In deaerated acetonitrile, the generated triplet lifetime $(\tau)$ with a value of $240 \mu$ s was obtained, while the transient was significantly quenched in aerated acetonitrile ( $\tau=280 \mathrm{~ns}$ ). Furthermore, we have performed another control experiment and found that in the presence of oxygen the photocurrent cannot be enhanced for $\mathrm{TiO}_{2}$-Zn-perylene SURMOF-Bodipy (without PMMA) due to the quenching of $\mathrm{O}_{2}$ (Figure S11).

Moreover, the chronoamperometric experiments were also performed by using a $430 \mathrm{~nm}$ blue laser (power $\approx 60 \mathrm{~mW} \cdot \mathrm{cm}^{-2}$ ). As shown in Figure S12, the transient photocurrent of $\sim 10 \mu \mathrm{A} \cdot \mathrm{cm}^{-2}$ for $\mathrm{TiO}_{2}$-Zn-perylene SURMOF-Bodipy/PMMA materials-based devices was nearly 2-fold higher than that of $\left(\sim 4.5 \mu \mathrm{A} \cdot \mathrm{cm}^{-2}\right)$ for $\mathrm{TiO}_{2}$-Zn-perylene SURMOF and $\sim 1.2 \mu \mathrm{A} \cdot \mathrm{cm}^{-2}$ for $\mathrm{TiO}_{2}$. The $\mathrm{TiO}_{2}-\mathrm{Zn}$-perylene SURMOF-Bodipy/PMMA device exhibited a linear response upon $430 \mathrm{~nm}$ blue light irradiation at low power intensity due to the faster triplet energy transfer from Bodipy to Zn-perylene SURMOF [23].

The overall photovoltaic performances of $\mathrm{TiO}_{2}-\mathrm{Zn}$-perylene SURMOF-Bodipy/PMMA device were examined as shown in Figure $\mathrm{S} 13$ and Table S2. The device using $\mathrm{TiO}_{2}-\mathrm{Zn}$-perylene SURMOF-Bodipy/PMMA as photoanode exhibits the best performances among the devices using $\mathrm{TiO}_{2}$-Zn-perylene SURMOF, $\mathrm{TiO}_{2}$-Bodipy/PMMA, and $\mathrm{TiO}_{2}$ as photoanode due to TTA-UC $[19,20]$. Although the device performance is not very impressive, in the present work, we demonstrated the strategy with the upconverting SURMOF-based system for solar energy conversion. It requires a lot of study to further develop the MOF thin film materials for PV applications. Further research efforts on the improvement of the device performances have been planned and will be carried out in the future.

\section{Conclusions}

In conclusion, we have fabricated a prototype Zn-perylene SURMOF material based TTA-UC device which is integrated with metal-free Bodipy sensitizer and glassy PMMA polymer. It has been demonstrated that the photocurrent can considerably be enhanced via TTA UC due the Zn-perylene SURMOF-Bodipy/PMMA materials-based devices. However, it also suggests a need for more extensive research efforts towards study of detailed mechanisms, exploration of suitable electrolytes, and optimization procedures for device based on these materials. The proposed investigation will further improve the potential for enhancing the efficiency of MOF thin film materials-based energy conversion devices. Thus, the dedicated efforts in such direction may raise the interest for solidified smart and hybrid materials based solar energy conversion devices.

Supplementary Materials: The following are available online at http:/ /www.mdpi.com/1996-1944/11/10/1868/s1.

Author Contributions: The manuscript was written through contributions of all authors. All authors have given approval to the final version of the manuscript.

Funding: Financial support by the Natural Science Foundation of China (NSFC 21673032), the Fundamental Research Funds for the Central Universities (DUT17LK21, DUT18RC(3)055), and the State Key Laboratory of Physical Chemistry of Solid Surfaces, Xiamen University (201507), is gratefully acknowledged.

Acknowledgments: We thank Jianzhang Zhao and Wenbo Yang for the synthesis of the Bodipy derivative.

Conflicts of Interest: The authors declare no conflict of interest. 


\section{References}

1. Hill, S.P.; Banerjee, T.; Dilbeck, T.; Hanson, K. Photon upconversion and photocurrent generation via self-assembly at organic-inorganic interfaces. J. Phys. Chem. Lett. 2015, 6, 4510-4517. [CrossRef] [PubMed]

2. Hill, S.P.; Dilbeck, T.; Baduell, E.; Hanson, K. Integrated Photon Upconversion Solar Cell via Molecular Self-Assembled Bilayers. ACS Energy Lett. 2016, 1, 3-8. [CrossRef]

3. Simpson, C.; Clarke, T.M.; MacQueen, R.W.; Cheng, Y.Y.; Trevitt, A.J.; Mozer, A.J.; Wagner, P.; Schmidt, T.W.; Nattestad, A. An intermediate band dye-sensitised solar cell using triplet-triplet annihilation. Phys. Chem. Chem. Phys. 2015, 17, 24826-24830. [CrossRef] [PubMed]

4. Shockley, W.; Queisser, H.J. Detailed balance limit of efficiency of p-n junction solar cells. J. Appl. Phys. 1961, 32, 510-519. [CrossRef]

5. Dilbeck, T.; Wang, J.C.; Zhou, Y.; Olsson, A.; Sykora, M.; Hanson, K. Elucidating the Energy- and Electron-Transfer Dynamics of Photon Upconversion in Self-Assembled Bilayers. J. Phys. Chem. C 2017, 121, 19690-19698. [CrossRef]

6. Wang, Z.; Knebel, A.; Grosjean, S.; Wagner, D.; Bräse, S.; Wöll, C.; Caro, J.; Heinke, L. Tunable molecular separation by nanoporous membranes. Nat. Commun. 2016, 7, 13872-13879. [CrossRef] [PubMed]

7. Wu, G.; Huang, J.; Zang, Y.; He, J.; Xu, G. Porous Field-Effect Transistors Based on a Semiconductive Metal-Organic Framework. J. Am. Chem. Soc. 2016, 1360-1363. [CrossRef] [PubMed]

8. Liu, H.L.; Chang, L.N.; Chen, L.Y.; Li, Y.W. Nanocomposites of Platinum/Metal-Organic Frameworks Coated with Metal-Organic Frameworks with Remarkably Enhanced Chemoselectivity for Cinnamaldehyde Hydrogenation. Chemcatchem 2016, 8, 946-951. [CrossRef]

9. Wang, Z.B.; Nminibapiel, D.; Shrestha, P.; Liu, J.X.; Guo, W.; Weidler, P.G.; Baumgart, H.; Wöll, C.; Redel, E. Resistive Switching Nanodevices Based on Metal-Organic Frameworks. Chemnanomat 2016, 2, 67-73. [CrossRef]

10. Kornienko, N.; Zhao, Y.; Kley, C.S.; Zhu, C.; Kim, D.; Lin, S.; Chang, C.J.; Yaghi, O.M.; Yang, P. Metal-organic frameworks for electrocatalytic reduction of carbon dioxide. J. Am. Chem. Soc. 2015, 137, 14129-14135. [CrossRef] [PubMed]

11. Choi, K.M.; Kim, D.; Rungtaweevoranit, B.; Trickett, C.A.; Barmanbek, J.T.D.; Alshammari, A.S.; Yang, P.; Yaghi, O.M. Plasmon-Enhanced Photocatalytic $\mathrm{CO}_{2}$ Conversion within Metal-Organic Frameworks under Visible Light. J. Am. Chem. Soc. 2017, 139, 356-362. [CrossRef] [PubMed]

12. Ye, L.; Liu, J.; Gao, Y.; Gong, C.; Addicoat, M.; Heine, T.; Wöll, C.; Sun, L. Highly oriented MOF thin film-based electrocatalytic device for the reduction of $\mathrm{CO}_{2}$ to $\mathrm{CO}$ exhibiting high faradaic efficiency. J. Mater. Chem. A 2016, 4, 15320-15326. [CrossRef]

13. Wang, M.; Liu, J.; Guo, C.; Gao, X.; Gong, C.; Wang, Y.; Liu, B.; Li, X.; Gurzadyan, G.G.; Sun, L. Metal-organic framework (ZIF-67) as efficient cocatalyst for photocatalytic reduction of $\mathrm{CO}_{2}$ : The role of morphology effect. J. Mater. Chem. A 2018, 6, 4768-4775. [CrossRef]

14. Miner, E.M.; Dincă, M. Metal-organic frameworks: Evolved oxygen evolution catalysts. Nat. Energy 2016, 1, 16186. [CrossRef]

15. Hod, I.; Deria, P.; Bury, W.; Mondloch, J.E.; Kung, C.W.; So, M.; Sampson, M.D.; Peters, A.W.; Kubiak, C.P.; Farha, O.K.; et al. A porous proton-relaying metal-organic framework material that accelerates electrochemical hydrogen evolution. Nat. Commun. 2015, 6, 8304-8313. [CrossRef] [PubMed]

16. Liu, J.X.; Zhou, W.C.; Liu, J.X.; Howard, I.; Kilibarda, G.; Schlabach, S.; Coupry, D.; Addicoat, M.; Yoneda, S.; Tsutsui, Y.; et al. Photoinduced Charge-Carrier Generation in Epitaxial MOF Thin Films: High Efficiency as a Result of an Indirect Electronic Band Gap? Angew. Chem. Int. Ed. 2015, 54, 7441-7445. [CrossRef] [PubMed]

17. Liu, J.X.; Zhou, W.C.; Liu, J.X.; Fujimori, Y.; Higashino, T.; Imahori, H.; Jiang, X.; Zhao, J.J.; Sakurai, T.; Hattori, Y.; et al. A new class of epitaxial porphyrin metal-organic framework thin films with extremely high photocarrier generation efficiency: promising materials for all-solid-state solar cells. J. Mater. Chem. A 2016, 4, 12739-12747. [CrossRef]

18. Ahrenholtz, S.R.; Epley, C.C.; Morris, A.J. Solvothermal Preparation of an Electrocatalytic Metalloporphyrin MOF Thin Film and its Redox Hopping Charge-Transfer Mechanism. J. Am. Chem. Soc. 2014, 136, 2464-2472. [CrossRef] [PubMed] 
19. Ahmad, S.; Liu, J.; Gong, C.; Zhao, J.; Sun, L. Photon Up-Conversion via Epitaxial Surface-Supported Metal-Organic Framework Thin Films with Enhanced Photocurrent. ACS Appl. Energy Mater. 2018, 1, 249-253. [CrossRef]

20. Oldenburg, M.; Turshatov, A.; Busko, D.; Wollgarten, S.; Adams, M.; Baroni, N.; Welle, A.; Redel, E.; Woll, C.; Richards, B.S.; et al. Photon Upconversion at Crystalline Organic-Organic Heterojunctions. Adv. Mater. 2016, 28, 8477-8482. [CrossRef] [PubMed]

21. Simon, Y.C.; Weder, C. Low-power photon upconversion through triplet-triplet annihilation in polymers. J. Mater. Chem. 2012, 22, 20817-20830. [CrossRef]

22. Gray, V.; Dzebo, D.; Abrahamsson, M.; Albinsson, B.; Moth-Poulsen, K. Triplet-triplet annihilation photon-upconversion: Towards solar energy applications. Phys. Chem. Chem. Phys. 2014, 16, 10345-10352. [CrossRef] [PubMed]

23. Svagan, A.J.; Busko, D.; Avlasevich, Y.; Glasser, G.; Baluschev, S.; Landfester, K. Photon energy upconverting nanopaper: A bioinspired oxygen protection strategy. ACS Nano 2014, 8, 8198-8207. [CrossRef] [PubMed]

24. Wang, J.C.; Hill, S.P.; Dilbeck, T.; Ogunsolu, O.O.; Banerjee, T.; Hanson, K. Multimolecular assemblies on high surface area metal oxides and their role in interfacial energy and electron transfer. Chem. Soc. Rev. 2018, 47, 104-148. [CrossRef] [PubMed]

25. Wu, W.H.; Guo, H.M.; Wu, W.T.; Ji, S.M.; Zhao, J.Z. Organic Triplet Sensitizer Library Derived from a Single Chromophore (BODIPY) with Long-Lived Triplet Excited State for Triplet-triplet Annihilation Based Upconversion. J. Org. Chem. 2011, 76, 7056-7064. [CrossRef] [PubMed]

26. Chen, Y.H.; Zhao, J.Z.; Xie, L.J.; Guo, H.M.; Li, Q.T. Thienyl-substituted BODIPYs with strong visible light-absorption and long-lived triplet excited states as organic triplet sensitizers for triplet-triplet annihilation upconversion. RSC Adv. 2012, 2, 3942-3953. [CrossRef]

27. Zhang, C.S.; Zhao, J.Z.; Wu, S.; Wang, Z.L.; Wu, W.H.; Ma, J.; Guo, S.; Huang, L. Intramolecular RET Enhanced Visible Light-Absorbing Bodipy Organic Triplet Photosensitizers and Application in Photooxidation and Triplet-triplet Annihilation Upconversion. J. Am. Chem. Soc. 2013, 135, 10566-10578. [CrossRef] [PubMed]

28. Rautela, R.; Joshi, N.K.; Novakovic, S.; Wong, W.W.H.; White, J.M.; Ghiggino, K.P.; Paige, M.F.; Steer, R.P. Determinants of the efficiency of photon upconversion by triplet-triplet annihilation in the solid state: zinc porphyrin derivatives in PVA. Phys. Chem. Chem Phys. 2017, 19, 23471-23482. [CrossRef] [PubMed]

29. Lee, C.Y.; Farha, O.K.; Hong, B.J.; Sarjeant, A.A.; Nguyen, S.T.; Hupp, J.T. Light-Harvesting Metal-Organic Frameworks (MOFs): Efficient Strut-to-Strut Energy Transfer in Bodipy and Porphyrin-Based MOFs. J. Am. Chem. Soc. 2011, 133, 15858-15861. [CrossRef] [PubMed]

30. Joblin, C.; Salama, F.; Allamandola, L. Absorption and emission spectroscopy of perylene $\left(\mathrm{C}_{20} \mathrm{H}_{12}\right)$ isolated in $\mathrm{Ne}, \mathrm{Ar}$, and $\mathrm{N}_{2}$ matrices. J. Chem. Phys. 1999, 110, 7287-7297. [CrossRef]

31. Summers, G.H.; Lefebvre, J.F.; Black, F.A.; Davies, E.S.; Gibson, E.A.; Pullerits, T.; Wood, C.J.; Zidek, K. Design and characterisation of bodipy sensitizers for dye-sensitized NiO solar cells. Phys. Chem. Chem. Phys. 2016, 18, 1059-1070. [CrossRef] [PubMed]

32. Ahmed, R.M. Optical Study on Poly(methylmethacrylate)/Poly(vinyl acetate) Blends. Int. J. Photoenergy 2009, 2009, 1-7. [CrossRef]

33. Karagiaridi, O.; Bury, W.; Mondloch, J.E.; Hupp, J.T.; Farha, O.K. Solvent-assisted linker exchange: an alternative to the de novo synthesis of unattainable metal-organic frameworks. Angew. Chem. 2014, 53, 4530-4540. [CrossRef] [PubMed]

34. Cheng, Y.Y.; Khoury, T.; Clady, R.G.C.R.; Tayebjee, M.J.Y.; Ekins-Daukes, N.J.; Crossley, M.J.; Schmidt, T.W. On the efficiency limit of triplet-triplet annihilation for photochemical upconversion. Phys. Chem. Chem. Phys. 2010, 12, 66-71. [CrossRef] [PubMed]

(C) 2018 by the authors. Licensee MDPI, Basel, Switzerland. This article is an open access article distributed under the terms and conditions of the Creative Commons Attribution (CC BY) license (http:/ / creativecommons.org/licenses/by/4.0/). 